\title{
Review : Teknologi Produksi Plastik Biodegradable Berbasis Pati Dan Pemanfaatannya Sebagai Bahan Kemasan
}

\author{
Review : Technology of Starch-Based Biodegradable Plastic Production and Its \\ Utilization as Packaging Materials
}

\author{
Nurmalisa Lisdayana, Dyah Ayu Larasati, dan Eka Nur'azmi Yunira \\ Program Studi Teknologi Industri Pertanian, Institut Teknologi Sumatera, Jalan Terusan Ryacudu, \\ Way Hui Jati Agung, Lampung Selatan 35365, Indonesia \\ e-mail: nurmalisalisdayana@tin.itera.ac.id
}

\begin{abstract}
Abstrak
Plastik merupakan bahan pengemas yang sangat sering digunakan karena sifatnya yang ringan, mudah dibentuk, serta murah harganya. Namun, tingginya penggunaan plastik menjadi permasalahan baru terutama terhadap lingkungan karena membutuhkan waktu yang sangat lama untuk dapat terdegradasi dan tidak ramah lingkungan. Permasalahan tersebut menjadi penyebab berkembangnya penelitian maupun produksi plastik yang dapat terdegrasasi secara alami atau plastik biodegradable. Penulisan review ini bertujuan untuk mengkaji metode produksi plastik biodegradable berbasis pati beserta aplikasinya. Penelitian tentang plastik biodegradable banyak banyak menggunakan polimer alami seperti pati dan selulosa sebagai bahan utama pembuatan plastik biodegradable karena ketersediannya yang melimpah. Namun pati memiliki kelemahan dalam sifat fisik dan mekaniknya sehingga memerlukan bahan tambahan lain, modifikasi pati, dan teknologi produksi untuk memperkuat sifat fisik dan mekanik plastik biodegradable. Metode produksi plastik biodegradable dapat dilakukan dengan metode casting, melt processing technique, thermoset processing, blow molding, injection molding, dan beberapa metode yang dilakukan untuk memproduksi plastik konvensional lainnya yang dapat disesuaikan untuk produksi plastik biodegradable. Aplikasi plastik biodegradable yang telah digunakan diantaranya berbentuk film, cup atau gelas, serta mangkuk yang digunakan untuk kemasan buah, produk minuman, serta salad. Penggunaan plastik biodegradable dapat ditingkatkan dengan sosialisasi penggunaan plastik biodegradable untuk mendukung pengembangan teknologi produksi bioplastik terutama di Indonesia.
\end{abstract}

Kata kunci: biodegrdable, kemasan, pati, plastik, selulosa.

ABSTRACT. Plastic is a packaging material that is very often used because of its lightweight, easily formed, and inexpensive. However, the use of plastic is non environmentally friendly because it takes a very long time to be degraded. These problems are the cause of the development of research or production of starch-based plastics that can be degraded naturally or biodegradable plastics. This study aims to examine the method of production of biodegradable starch-based plastic with its application. Research on biodegradable plastics uses a lot of natural polymers such as starch and cellulose as the main material for making biodegradable plastics because of their abundant availability. However, it has weaknesses in physical and mechanical properties that require additional materials, starch modification, and production technology to improve the physical and mechanical properties of biodegradable plastics. Biodegradable plastic production methods can be carried out by casting methods, melting processing techniques, thermoset processing, blow molding, injection molding, and several methods carried out to produce conventional plastics that can be adapted for the production of biodegradable plastics. Biodegradable plastic applications that have been used in the form of film, glass or glass, as well as a hood are used for packaging fruit, beverage products, and salads. The use of biodegradable plastics can be increased by socialization. The use of biodegradable plastics to support the development of leading bioplastic production technology in Indonesia.

Keywords: biodegradable, packaging, starch, plastic, cellulose.

\section{Pendahuluan}

Plastik merupakan salah satu bahan yang paling banyak digunakan sebagai kemasan karena ringan, mudah dibentuk, dan murah harganya. Namun tingginya penggunaan plastik menjadi permasalahan baru terhadap lingkungan dan kesehatan. Hal ini terjadi karena bahan plastik yang digunakan biasanya bersifat non-degradable atau tidak dapat terdegradasi secara alami. Selain itu kemasan plastik sering 
kali terjadi migrasi monomer dari bahan plastik pada makanan (Iriani et al. 2015) terutama dalam kondisi panas. Oleh karena itu diperlukan adanya alternatif bahan kemasan yang memiliki sifat seperti plastik namun dapat didegradasi secara alami atau disebut dengan plastik biodegradable.

Plastik biodegradable merupakan plastik yang dapat terurai secara alami oleh aktivitas mikroorganisme tanpa meninggalkan sisa yang beracun atau berbahaya bagi lingkungan (Suryati et al. 2016). Bahan alternatif yang dapat dijadikan pengganti bahan kemasan plastik nonbiodegradable adalah pati dan selulosa. Penggunaan pati dan selulosa sebagai matriks telah dilakukan sebagai pembuatan plastik biodegradable. Namun pengggunaan selulosa lebih banyak digunakan sebagai bahan pengisi atau filler karena sifatnya yang dapat meningkatkan sifat fisik dan mekanis plastik biodegradable. Penggunaan selulosa dalam pembuatan bioplastik membutuhkan beberapa modifikasi seperti pengecilan ukuran dan penambahan kimia untuk modifikasi selulosa. Turunan dari selulosa yang telah digunakan dalam pembuatan plastik biodegradable adalah nano kristalin selulosa (Arrieta et al. 2015), nanofiber selulosa (Lisdayana et al. 2018), dan selulosa asetat (Grunert et al. 2002). Selulosa sebagai bahan pengisi dalam plastik biodegradable dimodifikasikan dengan biopolimer lain terutama pati karena kemampuannya dalam membentuk plastik dan berasal dari alam.

Pati merupakan polimer yang dapat diperbarui, bersifat biodegradable, dan memiliki ketersediaan yang melimpah di alam. Pada umumnya pati digunakan untuk bahan pangan sekitar $60 \%$ dan non pangan $40 \%$ (Maryam et al. 2018). Saat ini penggunaan pati sering kali digunakan sebagai bahan matriks pembuatan plastik biodegradable, namun pati yang dijadikan sebagai matriks bahan kemasan memiliki beberapa kekurangan sehingga seringkali dimodifikasi dan dilakukan penambahan dari bahan lain yang berfungsi sebagai pengisi maupun agen penguat seperti selulosa. Proses pembuatan plastik biodegradable dengan penambahan bahan lain sebagai pengisi maupun agen penguat disebut juga sebagai komposit.

Selain itu pembuatan plastik biodegradable membutuhkan rekayasa proses pada bahan utama plastik yang dihasilkan memiliki produktivitas dan kualitas yang baik. Rekayasa proses pembuatan plastik biodegradable yang sering dilakukan antara lain crooss linking, asetilasi, meningkatkan kadar amilosa dengan natrium asetat (Cahyaningtyas et al. 2019). Rekayasa proses juga dilakukan pada proses blending karena bahan plastik biodegradable memiliki lebih dari satu fasa yang berbeda. Penggunaan metode proses pembuatan juga dapat dibentuk dengan cara seperti pembuatan plastik konvensional seperti injection molding, ekstrusi, thermoforming, dan blow molding.

Penulisan review ini bertujuan untuk mengkaji tentang metode produksi plastik biodegradable dengan berbagai sumber pati beserta aplikasinya berdasarkan referensi jurnal-jurnal bereputasi baik nasional maupun internasional. Hasil review dapat dijadikan landasan dalam penelitian produksi plastik biodegradable serta aplikasinya dalam kemasan produk pertanian.

\section{Metode Penelitian}

Penelitian ini dilakukan dengan studi pustaka menggunakan referensi jurnal-jurnal yang bereputasi baik nasional maupun internasional. Referensi yang digunakan dikelompokkan dengan beberapa tema seperti, plastik biodegradable, komposit, metode pembuatan plastik, dan aplikasi plastik sebagai kemasan produk.

\section{Hasil Dan Pembahasan \\ Plastik Biodegradable}

Plastik biodegradable merupakan plastik yang terbuat dari polimer-polimer yang mudah untuk diurai di alam (Tokiwa et al. 2009). Proses biodegradasi dipengaruhi oleh mikroorganisme yang ada di lingkungan. Kecepatan proses biodegradasi bergantung pada lingkungan di sekitar seperti suhu, tingkat oksigen, mikroba, dan iridiasi UV. Proses biodegradasi dilakukan dengan cara penguburan plastik ke dalam tanah, lumpur, limbah aktif, dan hidrolisi enzim.

Plastik biodegradable yang banyak diproduksi di pasaran menggunakan bahan baku PLA. PLA merupakan bioplastik yang diproduksi dari asam laktat yang berasal dari tanaman seperti jagung dan tebu, selain itu dapat didegradasi oleh berbagai mikroorganisme (Eubeler et al. 2010). Plastik biodegrable yang beredar di pasar, beberapa hanya bisa terdegradasi dengan kondisi lingkungan terbatas atau hanya akan terdegradasi dalam komposter industri. Plastik yang terbuat dari polimer tersebut akan mencemari lingkungan karena akan menumpuk dan tidak terdegradasi jika dibiarkan dalam tumpukan sampah tanpa proses degradasi menggunakan komposter industri.

Beberapa plastik biodegradable telah diproduksi dari bahan alam seperti pati termoplastik memiliki kemampuan terdegradasi secara alami. Pati termoplastik merupakan pati 
yang dicampur dengan air dan mendapatkan energi panas dan gaya geser sehingga mengalami destruksi (Zdrahala 1997). Pati termoplastik memiliki beberapa keterbatasan seperti kurangnya sifat mekanik dan sensitivitas terhadap air (Dean et al. 2008; Averous 2004) sehingga banyak peneliti sebelumnya yang mengkaji tentang modifikasi pati termoplastik untuk meningkatkan sifat mekanik dan sensivitas terhadap air. Modifikasi kimia yang telah berhasil dilakukan adalah modifikasi dengan asam askorbat (Carvalho et al. 2005) dan asam sitrat (Ma et al. 2009). Modifikasi kimia dengan asam askorbat dan asam sitrat dilakukan karena tidak beracun untuk dan dapat meningkatkan proses plastisisasi serta kompatibilitas antara pati termoplastik dan polimer lain seperti PLA (Ning et al. 2007).

\section{Plasticizers}

Plasticizers atau pemlastis komponen yang digunakan untuk melunakkan bahan plastik supaya mudah dibentuk. Pelmastis yang mudah ditemukan adalah air, namun penggunaan air sebagai bahan pemlastis satusatunya dalam suatu komposit plastik biodegradable tidak cukup sehingga perlu adanya pemlastis lain selain air. Bahan pemlastis yang dapat digunakan diantaranya gliserol, sorbitol, polietilen glikol, poliol, poly(oxyethylene)s, poly(oxypropylene)s, surfaktan non-ionik dan anionik.

Mekanisme plastisisasi adalah terjadinya dispersi molekul pemlastis ke dalam fase polimer. Proses dispersi akan berlangsung dalam skala molekul dan terbentuk larutan polimer pemlastis, hal ini disebut keadaan kompatibel. Interaksi antara pemlastis polimer dipengaruhi oleh sifat afinitas kedua komponen. Ketika afinitas polimer-pemlastis tinggi, maka molekul pemlastis akan terdifusi ke dalam bundel, sehingga molekul pemlastis akan berada di antara rantai polimer dan mempengaruhi mobilitas rantai (Efendi 2001). Penambahan plasticizer pada film biodegradable ditujukan untuk mengurangi kerapuhan yang disebabkan tekanan intermolecular yang tinggi.

\section{Komposit}

Komposit merupakan suatu hasil dari rekayasa yang terdiri dari 2 jenis material atau lebih dengan sifat fisik dan kimia yang berbeda dan menghasilkan material yang memiliki sifat yang berbeda dibandingkan dengan sifat material penyusunannya (Gibson 1994). Komposit telah banyak digunakan dalam berbagai bidang seperti pesawat ruang angkasa, produk pesawat canggih, peralatan medis, barang olahraga, plastik biodegradable, dll. Komposit terdiri dari dua komponen yaitu matriks dan komponen pengisi atau penguat. Matriks merupakan komponen yang berperan sebagai perekat atau pengikat dan pelindung bahan pengisi atau penguat dari kerusakan eksternal (Harper 1996). Sedangkan pengisi atau penguat berfungsi sebagai penguat dari matriks (Harper 1996). Matriks biasanya terbuat dari polimer alam, logam, dan keramik sedangkan pengisi atau penguat seringkali menggunakan serat alam dan bahan partikel. Serat yang seringkali digunakan untuk pengisi atau penguat berukuran sangat kecil sehingga memiliki homogenitas yang lebih tinggi dibandingkan dengan serat yang berukuran besar. Ukuran yang sering digunakan adalah nanometer sehingga komposit ini seringkali disebut dengan nanokomposit.

Nanokomposit digunakan dalam berbagai bidang seperti otomotif, kesehatan, maupun di plastik biodegradable. Nanokomposit yang berbentuk plastik biodegradable terutama yang memiliki pengisi atau penguat dari bahan alami bersifat biodegradable, biokompatible, dan memiliki sifat mekanik dan termal yang sangat baik (Ma et al. 2009). Pengisi atau penguat yang banyak digunakan adalah kitosan, nanolignin, nanoclay, dan nanoselulosa. Nanoselulosa merupakan agen penguat untuk polimer karena memiliki sifat mekaniknya yang baik, ketersediaan di alam yang melimpah, dapat diperbarui, dan bersifat biodegradable (Angles dan Dufresne 2000; Roohani et al. 2008). Nanoselulosa dapat meningkatkan modulus elastisitas film pati kentang yang dibuat dengan metode solution casting menjadi dua kali lipat (Moran et al. 2013). Dengan jumlah yang lebih banyak dibutuhkan untuk peningkatan yang sama pada pati termoplastik yang dihasilkan melalui twin-screw extrusion (Hietala et al. 2013).

\section{Metode produksi plastik biodegradable}

Pembentukan polimer menjadi plastik membutuhkan metode atau proses pembuatan yang sama dengan proses pembuatan plastik konvensional yang itu dengan compounding atau penggabungan antara bahan-bahan komposit plastik biodegradable. Compounding merupakan suatu proses untuk mempersiapkan bahan plastik mentah yang dicampur dengan bahan tambahan tertentu untuk memperkuat proses compounding. Bahan tambahan dapat berupa bahan pengisi ata penguat, pemlastis, pigmen warna dan lain-lain. Proses ini bertujuan untuk menyesuaikan sifat mekanik dan termal dari plastik agar sesuai dengan produk akhir dan membuat bahan plastik dapat diproses. 
Compounding sering dilakukan dalam twin screw extruder dengan proses mencampur komponen dan dihomogenisasi.

Bahan plastik yang telah melalui proses compounding diperlukan proses lebih lanjut untuk diubah menjadi produk jadi. Beberapa metode yang dapat dilakukan diantaranya ekstrusi, blown film extrusion, injection molding, blow molding, thermoforming, foams, casting, thermoset processing, dan metode lainnya seperi die casting dan injection compression moulding. Beberapa metode pembuatan plastik yang telah dilakukan oleh beberapa peneliti dapat dilihat pada tabel 1.

Tabel 1. Metode produksi dan materi penyusun utama plastik biodegradable

\begin{tabular}{|c|c|c|c|}
\hline $\begin{array}{c}\text { Material } \\
\text { penyusun } \\
\text { utama }\end{array}$ & Metode & Proses & Pustaka \\
\hline $\begin{array}{l}\text { Pati kentang } \\
\text { dan } \\
\text { biodegradable } \\
\text { polyesters }\end{array}$ & $\begin{array}{l}\text { Polymer melt } \\
\text { processing } \\
\text { techniques }\end{array}$ & $\begin{array}{l}\text { Pencampuran dilakukan dengan kecepatan screw } \\
30 \mathrm{rpm} \text { pada suhu } 90^{\circ} \mathrm{C} \text { dan aliran massa } 2 \mathrm{~kg} / \mathrm{jam} \text {. } \\
\text { Kemudian laju akan ditingkatkan setelah bahan } \\
\text { tercampur menjadi } 125 \mathrm{rpm} \text { dan } 130^{\circ} \mathrm{C} \text {. }\end{array}$ & $\begin{array}{l}\text { Avella et al. } \\
\text { (2005) }\end{array}$ \\
\hline $\begin{array}{l}\text { Pati jagung, } \\
\text { pati gandum, } \\
\text { dan pati } \\
\text { kentang }\end{array}$ & Melt extrution & $\begin{array}{l}\text { Campuran pati, gliserol, clay, dan air diekstrusi pada } \\
\text { kecepatan sekrup } 200 \mathrm{rpm} \text {. Kemudian ekstrudat } \\
\text { digiling menggunakan Wiley mill dan Ultra mill } \\
\text { untuk penggunaan lebih lanjut. Proses } \\
\text { pencampuran terjadi dengan aliran massa } 2 \mathrm{~kg} / \mathrm{jam} \\
\text { dan kecepatan sekrup } 30 \mathrm{rpm} \text { pada suhu } 90^{\circ} \mathrm{C} \text {. Laju } \\
\text { akan ditingkatkan setelah bahan tercampur menjadi } \\
125 \mathrm{rpm} \text { dan } 130^{\circ} \mathrm{C} \text {. }\end{array}$ & $\begin{array}{l}\text { Tang et al. } \\
\text { (2008) }\end{array}$ \\
\hline $\begin{array}{l}\text { Peti jagung, } \\
\text { pati sagu, dan } \\
\text { pati singkong }\end{array}$ & $\begin{array}{l}\text { Teknik casting } \\
\text { solution }\end{array}$ & $\begin{array}{l}\text { Proses pencampuran semua bahan dilakukan } \\
\text { dengan pengadukan mekanik dan suhu hingga } 95 \\
{ }^{\circ} \mathrm{C} \text {. }\end{array}$ & $\begin{array}{l}\text { Lisdayana } \\
\text { et al. } \\
(2018)\end{array}$ \\
\hline
\end{tabular}

\section{Aplikasi Plastik Biodegradable Sebagai Kemasan Produk}

Plastik biodegradable berpotensi untuk menjadi alternatif bahan kemasan selain plastik konvensional berdasarkan karakteristik fisik dan mekanik yang menyerupai plastik konvensional seperti sifat lentur dan ringan (Kamsiati et al. 2017) serta dapat terdegradasi secara alami. Beberapa penelitian yang telah menggunakan plastik biodegradable sebagai bahan kemasan produk diantaranya Blakistone dan Sand (2007) yang memanfaatkan plastik biodegradable berbasis selulosa sebagai kemasan buah Kiwi dan Iflah (2012) mengkaji tentang penundaan fase klimakterik buah tomat lebih lama dari pada dengan kemasan HDPE serta aplikasi terhadap paprika yang dapat bertahan hingga 12 hari. Selain itu beberapa peneliti juga banyak yang menggunakan PLA sebagai bahan kemasan biodegradable untuk kemasan produk seperti kemasan pada minuman yang berbentuk cup atau gelas (Sudesh dan Iwata 2008), kemasan pada salad yang berbentuk mangkuk atau bowl (Haugaard et al. 2003), dan untuk kemasan Yoghurt yang berbentuk jar (Jager 2010).
Plastik biodegradable juga dikembangkan oleh beberapa perusahaan untuk dikomersialkan seperti Enviplast, Avani Eco, dan juga perusaahan dari luar negeri yang memproduksi plastik biodegradable seperti Bioon (Italy), Novamont Italy, dan Arkema (Perancis). Namun pengguna plastik biodegradable lebih banyak di luar negeri daripada di Indonesia, bahkan perusahaan plastik biodegradable di Indonesia lebih banyak mengekspor produk mereka ke luar negeri (Kamsiati et al. 2017). Hal ini disebabkan kapasitas produksi plastik biodegradable belum maksimal sehingga menyebabkan harga plastik biodegradable lebih mahal Rp 200- 300 daripada harga plastik konvensional (Kamsiati et al. 2017).

Penggunaan plastik biodegradable di Indonesia dapat ditingkatkan dengan efisiensi produksi serta penggunaan bahan baku yang memiliki harga rendah karena ketersediaannya yang melimpah di Indonesia seperti pati dan selulosa. Pati dan selulosa memiliki ketersediaan yang melimpah di Indonesia bahkan banyak diantaranya merupakan hasil samping suatu produk seperti tandan kosong kelap sawit, bagas tebu, dan onggok dari tapioka. Selain itu modifikasi komposisi bahan dan metode 
produksi juga sangat diperlukan untuk menghasilkan plastik biodegradable dengan karakterisasi yang baik serta jumlah produksi yang optimal. Metode produksi dapat dikembangkan dengan cara menjalin kerjasama antara pemerintah dengan negara yang telah memiliki inovasi dalam produksi plastik biodegradable. Selain itu juga perlu digalakkan program pelarangan penggunaan plastik pada pusat perbelanjaan serta meningkatkan kampanye menggunakan plastik biodegradable.

\section{Kesimpulan}

Plastik biodegradable merupakan plastik yang dapat didegradasi secara alami dengan pengaruh lingkungan. Plastik biodegradable dibuat dengan memanfaatkan polimer-polimer alam yang dimodifikasi dengan teknologi pembuatan plastik konvensional menjadi komposit yang memiliki karakteristik yang menyerupai plastik konvensional. Metode produksi plastik biodegradable dapat dilakukan dengan metode casting, melt processing technique, thermoset processing, blow molding, injection molding, dan beberapa metode yang dilakukan untuk memproduksi plastik konvensional lainnya yang dapat disesuaikan untuk produksi plastik biodegradable. Aplikasi penggunaan plastik biodegradable sebagai kemasan telah banyak dilakukan di luar negeri yaitu dalam bentuk film, kantung, gelas, maupun mangkuk yang digunakan untuk mengemas buah, produk minuman serta salad. Penggunaan plastik biodegradable dapat ditingkatkan dengan sosialisasi penggunaan plastik biodegradable untuk mendukung pengembangan teknologi produksi bioplastik terutama di Indonesia.

\section{Daftar Pustaka}

Anglès, M. N. \& Dufresne, A. (2000) Plasticized Starch/Tunicin Whiskers

Nanocomposites. 1. Structural Analysis. Macromolecules, 33, 8344-8353.

Arrieta, M. P., Fortunati, E., Dominici, F., López J \& Kenny J. M. (2015). Bionanocomposite films based on plasticized PLA-PHB/cellulose nanocrystal blends. Carbohydrate Polymers, 121, 265-275

Avella, M., J. J., De Vlieger., M. E., Errico, S., Fischer, P., Vacca. \& M.G.Volpe. (2005). Biodegradable starch/clay nanocomposite films for food packaging application. Food Chemsitry, 93, 467-474.

Averous, L. (2004). Biodegradable multiphase systems based on plasticized starch: a review. J. Macromol. Sci, C44, 231-274.

Blakistone, B., \& Sand, C.K. (2007). Using sustainable packaging technologies to respond to consumer, retailer, and seafood industry needs. International Smoked Seafood Conference Proceedings, 75-79.

Cahyaningyas, A. A., Ermawati, R., Supeni, G., Syamani, F. A., Masruchin, N., Kusumaningrum, Q. B., Pramasari., Darmawan, T., Ismadi., Wibowo, E. S., Triwibowo, D., \& Kusumah, S. S. (2019). Modifikasi dan karakterisasi pati batang kelapa sawit secara hidrolisis sebagai bahan baku bioplastik. Jurnal Kimia dan Kemasan, 41(1), 37-44.

Carvalho, A. J. F., Zambon, M. D., Curvelo, A. A. S., \& Gandini, A. (2005). Thermoplastic starch modification during melt processing: hydrolysis catalyzed by carboxylic acids. Carbohydr. Polym. 62, 387-390.

Dean, K. M., Do, M. D., Petinakis, E., Yu, L. (2008). Key interactions in biodegradable thermoplastic starch/poly(vinyl alcohol)/montmorillonite micro- and nanocomposites. Compos. Sci. Technol, 68, 1453-1462.

Eubeler, J. P., Bernald, M, \& Knepper T. P. (2010). Enviromental biodegradation of synthetic polymers II. Biodegradation of different polymer groups. Trends in Analytical Chemistry, 29(2), 84-100.

Efendi, H. M. (2001). Modifikasi dan Penggunaan Pemlastis Turunan Asam Oleat pada Matriks Polivinil Klorida. Unpublished doctoral dissertation, Program Pasca Sarjana Universitas Sumatera Utara, Medan.

Gibson, R. F. (1994). Principles of composite material mechanism. New York: McGrawHill. Inc.

Grunert, M. \& Winter, W. T. (2002). Nanocomposites of cellulose acetate butyrate reinforced with cellulose nanocrystals. Journal of Polymers and the Environment, 101, 27-30.

Harper, A. C. (1996). Handbook of Plastics, Elastomers and Composites. Mc Graw Hill Componies, Inc.

Haugaard, V. K., Danielsen, B., \& Bertelsen, G. (2003). Impact of polylactate and poly(hydroxybutyrate) on food quality. European Food Research \& Technology, 216, 233-240.

Hietala, M., Mathew A.P., \& Oksman K. (2013). Bionanocomposites of thermoplastic starch and cellulose nanofibers manufactured using twin-screw extrusion. Eur Polym J, 49, 950-956.

Iflah, T., Sutrisno, \& Sunarti T. C. (2012). Pengaruh kemasan starch based plastics (Bioplastik) terhadap mutu tomat dan 
paprika selama penyimpanan dingin. Jurnal Teknologi Industri Pertanian, 22(3), 189-197.

Iriani E. S., Wahyuningsih, K., Sunarti, T. C., \& Permana, A. W. (2015). Sintesis nanoselulosa dari serat nanas dan aplikasinya sebagai nanofiller pada film berbasis polivinil alkohol. $J$ Penelitian Pascapanen Pertanian, 12(1), 11-19.

Jager, A. (2010). Ingeo $^{\mathrm{TM}}$ polylactide een natuurlijke keus, presentation given at VMT conference: green packaging.

Kamsiati, E., Herawati, H., Purwani, E. Y. (2017). Potensi pengembangan plastik biodegradable berbasis pati sagu dan ubi kayu di Indonesia. Jurnal Litbang Pertanian, 36(2), 67-76.

Lisdayana, N., Fahma, F., Sunarti T. C., \& Iriani E. S. (2018). Thermoplastic starch-PVA nanocomposite films reinforced with nanocellulose from oil palm empty fruit bunches (OPEFBs): effect of starch type. Journal of Natural Fibers, 1-12.

Ma, X., Chang, P.R., Yu, J., Stumborg, M., (2009). Properties of biodegradable citric acidmodified granular starch/thermoplastic pea starch composites. Carbohydr. Polym. $75,1-8$.

Maryam, Kasim, A., Novelina, \& Emriadi. (2018). Review : Teknologi preparasi pati nanopartikel dan aplikasinya dalam pengembangan komposit bioplastik. Majalah Ilmiah Teknologi Industri, 15(1), 36-56.

Moran, J. I., Vazquez, A., \& Cyras, V. P. (2013). Bio-nanocomposites based on derivatized potato starch and cellulose, preparation and characterization. J Mater Sci, 48, 7196-7203.

Ning, W., Jiugao, Y., Xiaofei, M., \& Ying, W. (2007). The influence of citric acid on the properties of thermoplastic starch/linear low-density polyethylene blends. Carbohydr. Polym. 67, 446-453.

Roohani, M., Habibi, Y., Belgacem, N. M., Ebrahim, G., Karimi, A. N. \& Dufresne, A. (2008). Cellulose whiskers reinforced polyvinyl alcohol copolymers nanocomposites. Eur. Polym. J. 44, 2489-2498.

Sudesh, K., \& Iwata, T. (2008). Sustainability of biobased and biodegradable plastics. CLEAN - Soil, Air, Water, 36, 433-442.

Suryati, Meriatna, \& Marlina. (2016). Optimasi Proses Pembuatan Bioplastik dari Pati Limbah Kulit Singkong. Jurnal Teknologi Kimia Unima, 5:1, 78 - 91.

Tang, X., Alavi, S., \& Herald, T. J. (2008). Barrier and mechanical Properties of Starch-Clay
Nanocomposite Films. Cereal Chem, 85(3), 433-439.

Tokiwa, Y., Calabia, B. P., Ugwu, C. U., \& Aiba, S. (2009). Review : Biodegrability of plastics. Molecular Science, 10, 3722-3742.

Zdrahala, R. J. (1997). Thermoplastic starch revisited. Structure/ property relationship for "dialed-in" biodegradability. Macromol. Symp, 123, 113-121. 